\title{
Survival rates and causes of mortality of leopards Panthera pardus in southern Africa
}

\author{
Lourens H. Swanepoel, Michael J. Somers, Wouter van Hoven \\ Monika Schiess-Meier, Cailey Owen, Andrei Snyman \\ Quinton Martins, Charl Senekal, Gerrie Camacho \\ WILLEM BOSHOFF and FrEDRIK DALERUM
}

\begin{abstract}
Estimation of survival rates is important for developing and evaluating conservation options for large carnivores. However, telemetry studies for large carnivores are often characterized by small sample sizes that limit meaningful conclusions. We used data from 10 published and 8 unpublished studies of leopards Panthera pardus in southern Africa to estimate survival rates and investigate causes of leopard mortality. Mean survival rates were significantly lower in non-protected (0.55 \pm SE 0.08$)$ compared to protected areas $(0.88 \pm 0.03)$. Inside protected areas juveniles had significantly lower survival $(0.39 \pm 0.10)$ compared to subadults $(0.86 \pm 0.07)$ and adults $(0.88 \pm 0.04)$. There was a greater difference in cause of death between protected and non-protected areas for females compared to males, with people being the dominant cause of mortality outside protected areas for both females and males. We suggest there is cause for concern regarding the sustainability of leopard populations in South Africa, as high female mortality may have severe demographic effects
\end{abstract}

LOURENS H. SWANEPoel (Corresponding author), Michael J. SOMERs*, Wouter VAN Hoven and FreDrik DALerum $\dagger$ Centre for Wildlife Management, University of Pretoria, Private Bag X21, Hatfield, South Africa

E-mail lourens.swanepoel@up.ac.za

MoniKa SCHIEsS-MeIER Institute of Evolutionary Biology and Environmental Studies, University of Zurich, Winterthurerstrasse, Switzerland, and Leopard Ecology \& Conservation, Khutse Game Reserve, Botswana

CAILEy Owen School of Life Sciences, University of KwaZulu-Natal, Westville Campus, Durban, South Africa

ANDREI SNYMAN School of Natural Resources, University of Nebraska, Lincoln, Nebraska, USA

Quinton Martins The Cape Leopard Trust, Sun Valley, South Africa, and Department of Conservation Ecology \& Entomology, Faculty of AgriSciences, University of Stellenbosch, South Africa

Charl Senekal Hlambanyathi Leopard Project, Pongola, South Africa

Gerrie Camacho Terrestrial Scientific Services, Mpumalanga Tourism and Parks Agency, Lydenburg, South Africa

WiLlem Boshoff Biodiversity Scientific Support, North West Department of Economic Development, Environment, Conservation and Tourism, Mabato, South Africa

${ }^{*}$ Also at: Centre for Invasive Biology, University of Pretoria, Hatfield, South Africa

$\dagger$ Also at: Mammal Research Institute, University of Pretoria, Hatfield, South Africa

Received 27 June 2013. Revision requested 6 August 2013.

Accepted 6 September 2013. First published online 15 August 2014. and a large proportion of suitable leopard habitat lies in non-protected areas. However, because a large proportion of deaths outside protected areas were attributed to deliberate killing by people, we suggest that management interventions may have the potential to increase leopard survival dramatically. We therefore stress the urgency to initiate actions, such as conflict mitigation programmes, to increase leopard survival in non-protected areas.

Keywords Africa, conflict, Cox proportional model, leopard, mortality, Panthera pardus, survival rate

This paper contains supplementary material that can be found online at http://journals.cambridge.org

\section{Introduction}

There is compelling evidence that large carnivores are 1 important in regulating terrestrial ecosystems (Ripple \& Beschta, 2012). However, large carnivores are vulnerable to several forms of human-caused mortality, which are often biased towards adults (Treves \& Karanth, 2003). Because the majority of large carnivores evolved under conditions of high adult survival (Weaver et al., 1996), changes in adult survival can have serious consequences for the long-term persistence of carnivore populations (Dalerum et al., 2008). Consequently, adult-biased killing has the potential to threaten population viability (e.g. Andrén et al., 2006).

The leopard Panthera pardus is a large generalist felid with a wide geographical distribution in Africa and tropical Asia (Henschel et al., 2008). In South Africa leopards are well adapted to inhabit human-dominated landscapes and are frequently found outside protected areas (Swanepoel et al., 2013). Even though non-protected areas are important for leopard conservation in South Africa (Swanepoel et al., 2013), leopards are often killed during conflict with farmers (Balme et al., 2009). Furthermore, leopards are prized specimens in the trophy hunting industry and a large number are poached for their skin (Balme, 2009). As hunting and other human-induced mortality can be additive rather than compensatory to natural mortality (Krebs et al., 2004), it can have negative 


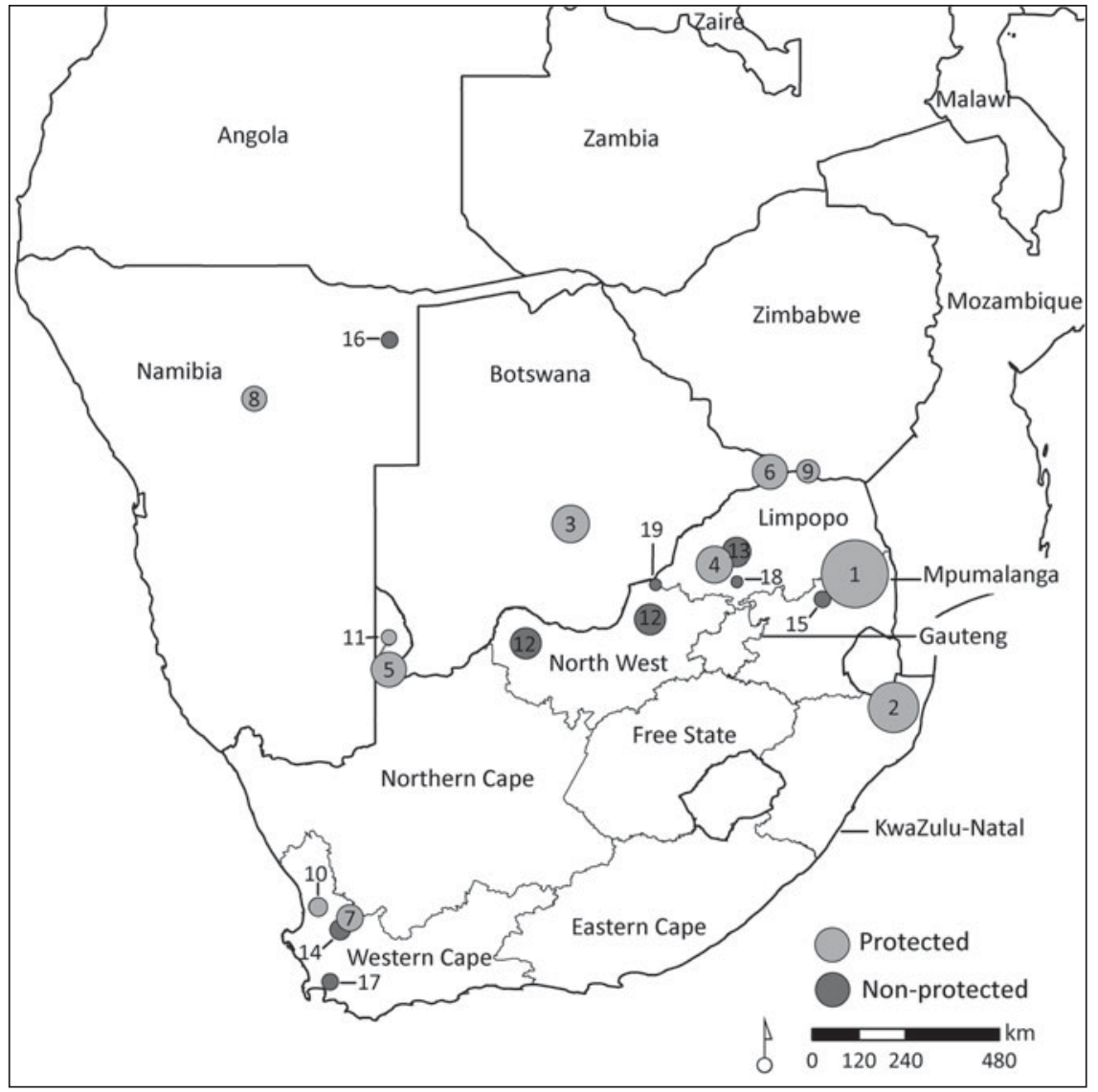

FIG. 1 Sites in southern Africa where 162 leopards Panthera pardus were monitored for a total of 195 leopardyears between 1985 and 2010. Numbers in circles correspond to site numbers in Supplementary Table $\mathrm{S}$, and circle size is proportional to the number of leopard-years monitored. effects on long-term population viability (Creel \& Rotella, 2010). Therefore, to adequately address the conservation needs of leopards it is also important to identify the primary causes of mortality. Furthermore, survival rates of carnivores in non-protected areas are generally low, which may impede conservation programmes (Krebs et al., 2004; Andrén et al., 2006). A better understanding of rates of survival and causes of mortality in non-protected and protected areas is therefore crucial for our ability to develop sustainable management strategies for leopards in southern Africa.

Studying large carnivores is difficult and costly, and most studies never obtain sufficient sample sizes for survival analysis (Krebs et al., 2004). To date, only two individual studies have been able to estimate survival and cause-specific mortality for leopards (Bailey, 2005; Balme, 2009), and both were largely restricted to protected areas. Consequently little is known about leopard survival rates in non-protected areas across southern Africa. The majority of leopard studies have not been able to collect sufficient information on survival and mortality to enable meaningful conclusions. In this study we therefore combined data from several unpublished and published studies to attain sufficient sample sizes to estimate survival and to quantify causes of leopard mortality in non-protected and protected areas in southern Africa.

\section{Methods}

\section{Contributing studies}

We collated leopard survival data from eight unpublished and 10 published studies in southern Africa, providing data for 162 leopards, spanning multiple age classes, monitored for 195 leopard-years (Fig. 1, Supplementary Table S1). The leopards were monitored in South Africa (126), Botswana (29) and Namibia (7). The data included 34 leopards in nonprotected and 128 in protected areas. The studies used leopards fitted with either VHF or global positioning system (GPS) collars, as well as a number of animals monitored without telemetry equipment. The data did not include collared juveniles. Data for juveniles were instead obtained from four collared breeding females with 14 juveniles, and additional visual monitoring data were available for six females with 14 juveniles. Leopards fitted with VHF collars were relocated at least twice per month. For GPS-collared animals, data were downloaded at least on a bi-weekly basis. Most GPS or VHF collars were supplied with mortality sensors, increasing the detection of leopards that died. At two studies, in Karongwe and Hlambanyathi game reserves, leopards where habituated to such an extent that some focal animals could be located once per week without telemetry equipment. For each animal we recorded date of collaring 
TABLE 1 Survival rates $( \pm S E)$ for leopard Panthera pardus sex and age classes in protected and non-protected areas in southern Africa (Fig. 1). Number of leopards is those in each sex and age class used to estimate survival rates.

\begin{tabular}{|c|c|c|c|c|c|c|}
\hline & \multicolumn{3}{|l|}{ Protected } & \multicolumn{3}{|c|}{ Non-protected } \\
\hline & Adult & Subadult & Juvenile* & Adult & Subadult & Juvenile \\
\hline \multicolumn{7}{|c|}{ Survival rates } \\
\hline Male & $0.94 \pm 0.04$ & $0.80 \pm 0.12$ & & $0.59 \pm 0.10$ & $0.48 \pm 0.21$ & \\
\hline Female & $0.86 \pm 0.05$ & $0.93 \pm 0.07$ & & $0.57 \pm 0.14$ & $0.18 \pm 0.13$ & \\
\hline Unknown & & & $0.39 \pm 0.10$ & & & \\
\hline \multicolumn{7}{|c|}{ Number of leopards } \\
\hline Male & 31 & 14 & & 15 & 5 & \\
\hline Female & 41 & 14 & & 9 & 5 & \\
\hline Unknown & & & 28 & & & \\
\hline
\end{tabular}

${ }^{\star}$ Juveniles were not sexed and data were only available for protected areas.

or start of monitoring, conservation status of the study site (i.e. protected or non-protected), age, sex, date the animal died or was last observed alive, and cause of death.

\section{Survival rates}

Leopards were classified into three age classes: juveniles (o-12 months), subadults (12-36 months) and adults (>36 months; Bailey, 2005). Individuals for which contact was lost or that were still alive at the end of each study period were censored in the analyses; i.e. they were coded as having an unknown time of death but as having survived until at least the last observation. Some leopards were captured as juveniles or subadults and were subsequently entered into the older age class as they matured. This means that although we had data for 162 individuals our survival data set for analysis consisted of 168 entries (Supplementary Table S1).

Mortality was detected when collars transmitted inactivity for prolonged periods, when individuals that were tracked for prolonged periods with fully functional collars that had unexpired batteries suddenly disappeared $(\mathrm{n}=3)$, or when individuals disappeared in study areas where people were hostile towards leopards and searches yielded no signal $(n=2)$. At most of these study sites there was camera trapping in conjunction with telemetry, which helped to confirm that the individual had physically disappeared. On all other occasions when mortality was not confirmed we regarded leopards as having had an unknown fate and they were subsequently censored in the analyses. Causes of juvenile ( $<12$ months) mortality could only be determined by monitoring adult females with juveniles. Five leopards collared inside protected areas died when they subsequently left the protected areas. We right censored these individuals on the date they left the reserve and subsequently left censored them into the non-protected population on the first date or relocation in the non-protected area. Litter sizes and dates of births were estimated by visual inspection of den sites, sightings of juveniles or investigating juvenile tracks associated with monitored females. Juvenile mortality was determined if their mother died and cubs subsequently disappeared $(n=1)$, if females with juveniles were repeatedly detected without juveniles $(n=8)$ and in incidents where violent deaths of juveniles were witnessed $(n=5)$.

\section{Causes of mortality}

We combined information from these studies with 52 additional published records of leopard mortality (Norton \& Lawson, 1985; Norton \& Henley, 1987; Stander et al., 1997; Bailey, 2005; Steyn, 2008; Balme, 2009). These data included 122 leopard mortality events for which the cause of mortality was known, all derived from collared animals except the two studies that only had data from direct observations.

Four major categories were used to describe cause of death: natural, accidental killing by people, and legal and illegal killing by people. Each of these was further categorized into subcategories. Natural mortality was categorized as intraspecific killing, interspecific killing and unknown natural causes. A death was categorized as interspecific killing if there were other large carnivores (e.g. lions Panthera leo) in immediate proximity to the mortality, if the mortality event was observed directly, or if there was evidence on the carcass or at the site of the event (e.g. bite wounds or animal tracks). Intraspecific killing was confirmed by either direct observation of fatal fights, indirect evidence such as typical feeding and killing behaviour of leopards (e.g. drag marks, plucked fur; Steyn \& Funston, 2006) or if two leopards were found close to each other and one subsequently died from fatal wounds. Leopards were categorized as having died from unknown natural causes (i. e. not caused by people) if no debilitating injuries were present, no bite wounds were found and there were no signs of struggle. Road kills were categorized as accidental killing by people, the only type of accidental killing detected. Legal killing consisted of killing of problem animals and trophy 
hunts. Data for these causes of death were available from the relevant authorities. Illegal killing was categorized as snared, poisoned or unknown illegal killing. Snared leopards were either found dead in a snare or were found to have died from snaring-related injuries such as infected legs. Poisoning was either confirmed by autopsy or if we found poison-laced carcasses, meat or other dead poisoned animals nearby. Unknown illegal killing included cases in which collars were found in strange places (e.g. in a dam), collars were found cut and destroyed in the field, or there was direct evidence for the cause of death, such as a gunshot wound. In most cases of leopards killed illegally for unknown reasons we relied on confirmation from local landowners, staff workers, community members and research technicians that animals had been killed $(n=10)$. Juvenile mortality was categorized and determined as for adult and subadult natural mortality but we noted if infanticide events (i.e. intraspecific killing) were likely to have been caused by sexually selected infanticide (sensu Hrdy, 1979) as this has received some attention in literature regarding large carnivore management (e.g. brown bear Ursus arctos, Swenson et al., 1997; lion, Whitman et al., 2004; leopard, Balme et al., 2013). A mortality event was categorized as sexually selected infanticide if infanticidal behaviour of an adult male was observed $(n=4)$, if juveniles were found dead and a collared adult male was found nearby $(\mathrm{n}=1)$, or if a resident male was displaced by a rival and the resident female's juveniles subsequently died or went missing $(n=4)$.

\section{Data analyses}

We used semi-parmetric Cox proportional-hazard models, rather than full parametric models, to calculate age- and sex-specific survival in non-protected and protected areas and to evaluate the effects of conservation status, age and sex on survival (Therneau \& Grambsch, 2010). We chose the semi-parametric model because our survival data were collated from various sources and time periods, meaning that not all animals were collared at the same time and under the same conditions. This made it difficult to estimate the baseline hazard (i.e. the risk of death at time $=t$ when all explanatory variables are at zero) needed for full parametric models (Murray, 2006). Under such conditions the Cox proportional-hazard model is an attractive method as there is no need to specify the baseline hazard function (Therneau \& Grambsch, 2010). We pooled data across the studies and approached the analysis as a staggered entry design (Pollock et al., 1989). We created two separate models. In the first we fitted conservation status, age, sex and all interaction effects. As we did not have information of the sex of juveniles we restricted this analysis to subadults and adults. In the second model we evaluated the effect of leopard age, including all age classes. We restricted this analysis to leopards inside protected areas as we had no data on juveniles from nonprotected areas, pooling male and female subadults and adults. As some individuals were monitored across more than one age class we added individuals as a random effect in the models to control for non-independence within individuals. We also controlled for non-independence within each study by adding the study location as a random effect. The main and interaction effects were evaluated by likelihood ratio tests after sequential deletions of model terms (Crawley, 2002). Both the model on the effects of conservation status, age and $\operatorname{sex}\left(\chi^{2}=2.91, \mathrm{df}=1, \mathrm{P}=1.00\right)$ and the model evaluating the effect of age inside protected areas $\left(\chi^{2}=0.007, \mathrm{df}=1, \mathrm{P}=0.997\right)$ met proportional hazard assumptions, based on scaled Schoenfeld residuals (Grambsch \& Therneau, 1994). We report survival rates as mean \pm SE.

We used cumulative link mixed models with a logit link function and a multinomial error to investigate the effect of conservation status, age and sex on the cause of leopard mortality (Agresti, 2010). Because the data source (i.e. field data or published data) had no effect on cause of death $\left(\chi^{2}=0.34, \mathrm{df}=1, \mathrm{P}=0.56\right)$ we used data pooled from both sources in these analyses. We treated cause of death as an ordinal categorical response variable with the following order: natural mortality, accidental mortality, legal mortality and illegal mortality. We fitted conservation status, age, sex, as well as all interactions as fixed effects. To account for non-independence within study sites, we added study site as a random effect in the model. We used sequential likelihood ratio tests to evaluate the fixed effects in the model. Statistical analyses were conducted in $R$ v. 2.4.13 (R Development Core Team, 2011) using functions in the packages survival (Therneau, 2012), multcomp (Hothorn et al., 2012) and ordinal (Christensen, 2011).

\section{Results}

\section{Survival}

Conservation status had a significant effect on survival $\left(\chi^{2}=24.37, \mathrm{df}=1, \mathrm{P}<0.001\right)$, with survival rates for all age and sex classes consistently lower in non-protected compared to protected areas (Fig. 2). Combined annual survival rates for adults and subadults were $0.55 \pm \mathrm{SE} 0.16$ for non-protected areas compared to $0.88 \pm \mathrm{SE} 0.04$ for protected areas. There was no significant three-way interaction between conservation status, age and $\operatorname{sex}\left(\chi^{2}=2.89, \mathrm{df}=1\right.$, $\mathrm{P}=0.088)$, nor significant two-way interactions between conservation status and age $\left(\chi^{2}=0.15, \mathrm{df}=1, \mathrm{P}=0.70\right)$, conservation status and $\operatorname{sex}\left(\chi^{2}=0.04, \mathrm{df}=1, \mathrm{P}=0.84\right)$ or age and $\operatorname{sex}\left(\chi^{2}=0.22, \mathrm{df}=1, \mathrm{P}=0.64\right)$. There were similarly no effects of age $\left(\chi^{2}=1.38, \mathrm{df}=1, \mathrm{P}=0.24\right)$ or 
(a) Adult male

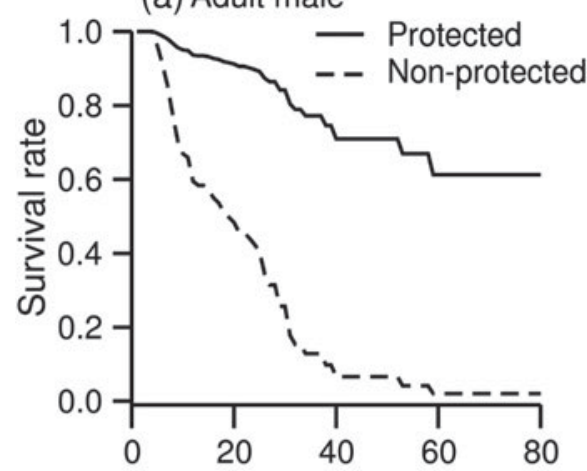

(c) Subadult male

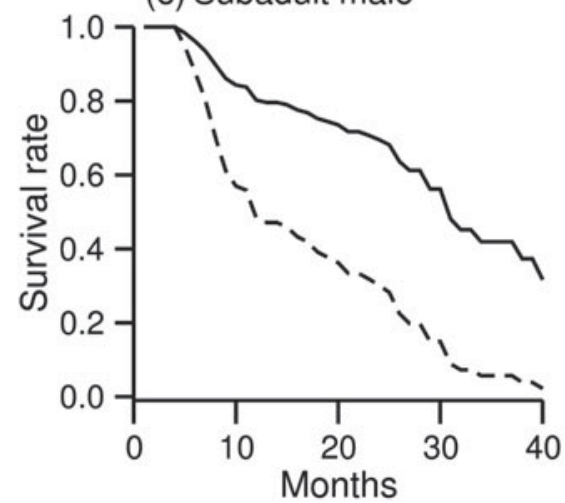

(b) Adult female

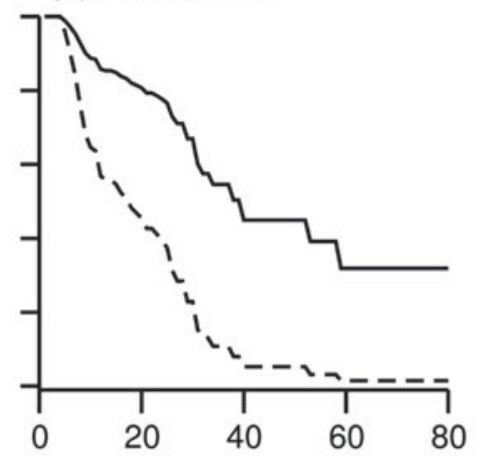

(d) Subadult female

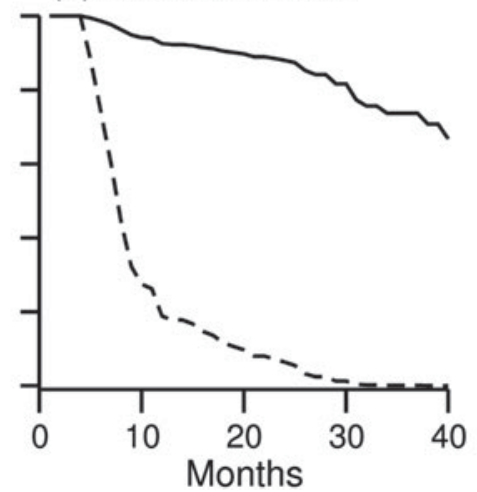

(e) Juveniles

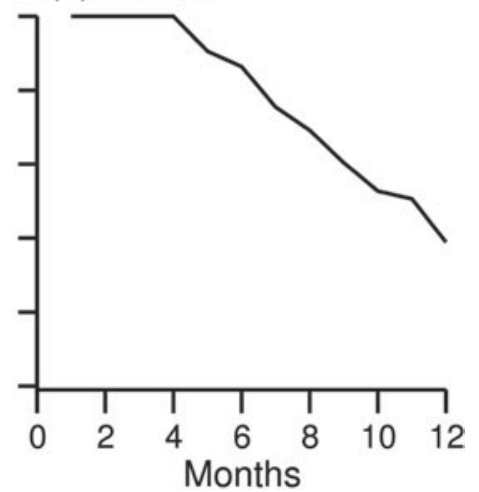

FIG. 2 Survival rate of leopards in protected and non-protected areas in southern Africa for (a) adult males, (b) adult females, (c) subadult males, (d) subadult females and (e) juveniles, estimated by fitting Cox proportional hazard models to leopard monitoring data. Data for juveniles were only available for protected areas.

sex $\left(\chi^{2}=1.59, \mathrm{df}=1, \mathrm{P}=0.21\right)$ in this model. Within protected areas, however, there was a significant effect of age on survival $\left(\chi^{2}=23.65, \mathrm{df}=2, \mathrm{P}<0.001\right)$, and juveniles had a significantly lower survival than adults (hazard ratio 7.22, $z=4.30, \mathrm{P}<0.001$ ) and subadults (hazard ratio 8.56, $z=2.54, \mathrm{P}=0.02$ ), although survival did not differ between adults and subadults (hazard ratio 1.18, $z=0.29, \mathrm{P}=0.94$; Table 1). Five leopards died when they left the protected areas: one adult female killed in a snare, one adult male and one adult female in road kills, one subadult male hunted and one adult male killed in problem animal control action. Estimated survival rates for non-protected areas, particularly for subadult females, were characterized by large standard errors and subsequent low precision of the survival estimates (Table 1).

\section{Causes of mortality}

There was a significant interaction effect of sex and conservation status on cause of death $\left(\chi^{2}=4.12, \mathrm{df}=1\right.$, $\mathrm{P}=0.040$ ), with a more pronounced difference in causes of death between protected and non-protected areas for females compared to males $(\beta=-2.700, z=-1.88$,
$\mathrm{P}=0.060$ ). In protected areas females died more often from natural causes compared to males, whereas both females and males in non-protected areas died most often from human-related causes (Table 2). However, although a large proportion of female mortality was accidental (road kills), the major cause of death for males was deliberate removal of individuals. Neither the three-way effect of conservation status, age and $\operatorname{sex}\left(\chi^{2}=0, \mathrm{df}=1, \mathrm{P}=0.999\right)$, any of the other two-way interactions ( $\operatorname{sex} \mathrm{x}$ age: $\chi^{2}=0.769$, $\mathrm{df}=1, \mathrm{P}=0.380$; age $\mathrm{x}$ conservation area: $\chi^{2}=3.45, \mathrm{df}=1$, $\mathrm{P}=0.063)$, nor the main effect of age $\left(\chi^{2}=2.591, \mathrm{df}=1\right.$, $\mathrm{P}=0.107$ ) were significant.

The majority of natural mortality in protected areas was attributed to intraspecific killing (Table 2). For juveniles $52 \%$ of mortalities were attributed to sexually selected infanticide (Table 2). Interspecific mortality included killing by lions, porcupines Hystrix africaeaustralis, spotted hyaenas Crocuta crocuta and Nile crocodiles Crocodylus niloticus. In non-protected areas road kills accounted for all accidental mortality, and hunting and problem animal control accounted for the legally killed leopards (Table 2). Unknown causes of illegal killing accounted for most of the illegally killed leopards in non-protected areas whereas 
TABLE 2 Identifiable causes of natural and accidental mortality, and legal and illegal killing by people for monitored leopards of known sex and age classes in protected and non-protected areas in southern Africa (Fig. 1).

\begin{tabular}{|c|c|c|c|c|c|c|c|c|c|}
\hline & \multicolumn{3}{|l|}{ Natural } & \multirow{2}{*}{$\frac{\text { Accidental }}{\text { Road kills }}$} & \multicolumn{2}{|l|}{ Legal } & \multicolumn{3}{|l|}{ Illegal } \\
\hline & Interspecific & Intraspecific & Unknown $^{1}$ & & $\mathrm{DCA}^{2}$ & Hunts & Poison & Unknown $^{3}$ & Snare \\
\hline \multicolumn{10}{|l|}{ Females } \\
\hline Protected (\%) & 21 & 43 & 32 & & & & 4 & & \\
\hline No. of adults & 6 & 9 & 6 & & & & 1 & & \\
\hline No. of subadults & & 3 & 3 & & & & & & \\
\hline Non-protected (\%) & 4 & & & 26 & 9 & 17 & 13 & 17 & 13 \\
\hline No. of adults & 1 & & & 6 & 1 & 4 & 2 & 3 & 3 \\
\hline No. of subadults & & & & & 1 & & 1 & 1 & \\
\hline \multicolumn{10}{|l|}{ Males } \\
\hline Protected (\%) & 30 & 20 & 20 & & 10 & & & 5 & 15 \\
\hline No. of adults & 4 & 1 & 3 & & 2 & & & 1 & 3 \\
\hline No. of subadults & 2 & 3 & 1 & & & & & & \\
\hline Non-protected (\%) & 6 & & & 6 & 11 & 27 & & 44 & 6 \\
\hline No. of adults & & & & 1 & 2 & 4 & & 7 & 1 \\
\hline No. of subadults & 1 & & & & & 1 & & 1 & \\
\hline \multicolumn{10}{|l|}{ Juveniles $^{4}$} \\
\hline Protected (\%) & 6 & 76 & 18 & & & & & & \\
\hline Number & 1 & $13^{5}$ & 3 & & & & & & \\
\hline
\end{tabular}

${ }^{1}$ Cases where leopards died of natural causes but the specific cause could not be determined (e.g. disease or starvation).

${ }^{2}$ Damage-causing animals; e.g. leopards killed under permits to remove animals responsible for predation on livestock and game.

${ }^{3}$ Cases in which leopards were killed illegally; in most cases cause of death was not known and death of animal was confirmed by either informants, destroyed collars located or collars found in strange places (e.g. in a dam).

${ }^{4}$ Juveniles were not categorized by sex.

${ }^{5}$ Includes nine cases of sexually selected infanticide.

snaring was the major cause of illegal mortality in protected areas (Table 2).

\section{Discussion}

\section{Survival}

Our results indicate that leopards had lower survival in non-protected compared to protected areas, and that this lower survival was largely caused by higher human-related mortality. Our study therefore concurs with other studies in which survival of carnivores inhabiting multi-use landscapes is mainly determined by human activities (e.g. wolverines Gulo gulo, Krebs et al., 2004; Eurasian lynx Lynx lynx, Andrén et al., 2006). Although the precision of survival estimates in non-protected areas was low for specific sex and age classes, our data are informative for qualitative interpretation of differences in survival between protected and non-protected areas. Furthermore, our results include the first empirical estimates of survival of leopards outside protected areas, and although quantification of the extent of differences in survival between protected and non-protected areas would benefit from further study, we suggest that the low survival rates in non-protected areas may be a cause of concern as mortality rates $>30 \%$ for solitary carnivores could lead to population declines (Stoner et al., 2006; Balme et al., 2009). Our survival estimates for protected areas were similar to some previous studies (Bailey, 2005; Balme et al., 2009) but lower than those proposed by Eberhardt (2002; adult female survival $>0.95$ ).

Juvenile survival was lower than recorded by some previous studies in protected areas (Bailey, 2005; Balme, 2009) but similar to a recent estimate from a long-term data set (Balme et al., 2013). Our study thus indicates that juvenile survival rates can be much lower than previously thought (e.g. Balme et al., 2013). Moreover, the infanticide rate was higher than the only other study reporting infanticide (Balme et al., 2013). High rates of sexually selected infanticide can be a result of management actions that increase turnover among adult territorial males (e.g. hunting; Swenson et al., 1997; Balme et al., 2009). As lifetime reproductive success of female leopards is closely related to cub survival (Balme et al., 2013), high levels of infanticide can lead to a decline in population growth and population viability (Whitman et al., 2004).

In polygynous species males are predicted to exhibit lower survival as a result of the cost of defending territories, dispersal and competition for females (Bailey, 2005). However, there was no effect of sex on survival in our analyses, although the sexes differed in the causes of death. This is a cause for concern, as adult female mortality generally has greater demographic impacts than adult male mortality (Dalerum et al., 2008). We suggest three, not 
necessarily mutually exclusive, explanations for the lack of male-biased mortality. Firstly, human-caused mortality among males could have increased intraspecific mortality in females by disrupting long-term social relationships and associated social structure (Stoner et al., 2006; Balme et al., 2010). For example, intraspecific predation was one of the leading causes of death among adult female cougars Puma concolor during periods of high harvest pressure (Stoner et al., 2006). Secondly, the lack of differences in survival rates between the sexes could have been caused by state dependent biological factors that made females more mortality prone than predicted from their mating system and sexspecific behavioural characteristics (Baker \& Thompson, 2007). Such factors could, for instance, include a higher spatial philopatry in females and associated increased risk of persecution if the animal is residing within a conflict prone area, or breeding-related shifts in diet and behaviour that could increase mortality risks and offset the increased mortality expected by males. Thirdly, our results could be an artefact caused by high incidences of censoring and low sample sizes, particularly within study sites and time periods.

\section{Causes of mortality}

People were responsible for the majority of leopard mortalities in non-protected areas, which concurs with studies of other large carnivores in human-dominated landscapes (Woodroffe \& Ginsberg, 1998; Andrén et al., 2006). Combined with elevated mortality estimates outside protected areas, our results suggest that persecution may potentially have demographic consequences and subsequently be a threat to the sustainability of leopard populations in such areas (Balme et al., 2009, 2010; Chase-Grey, 2011). Humancaused mortality in non-protected areas was largely accounted for by deliberate removals, which seem to be driven by a demand for trophies, carnivore conflict and poaching for leopard skins (Balme et al., 2012; Thorn et al., 2012). Furthermore, a large number of persecuted leopards were killed illegally, which is difficult to control and can therefore be of particular management concern (Thorn et al., 2012). Illegal killing of leopards seems to be related to the type of conflict, permit regulations and lack of law compliance (Chase-Grey, 2011). For example, some provincial authorities do not regard predation on free-ranging game (e.g. KwaZulu-Natal; Balme et al., 2009) as a reason to issue permits to kill problem leopards. Under such a system landowners are more inclined to kill leopards illegally when they detect predation on free-ranging game (Chase-Grey, 2011; Thorn et al., 2012). Similarly, the time constraints imposed by problem animal permits (some valid for 30 days), the time needed to apply for a permit, and low policy compliance prompt landowners to kill leopards illegally (Chase-Grey, 2011).
Females and males differed in the effect of conservation status of the area on cause of death. Inside protected areas our results concur with other studies of leopards in which females died more often from natural than from humaninduced causes, whereas males also died from deliberate removals (Bailey, 2005; Balme et al., 2009). In non-protected areas, however, people were the major cause of mortality of both sexes. This is unexpected as females are not preferred by hunters (Balme et al., 2012), nor do they have wideranging behaviour that could bring them into contact with hostile farmers (Balme et al., 2009). We propose that the philopatric behaviour of females may increase their risk of being killed as damage-causing animals, as resident animals focus their predation on fewer farms. Such predation conflicts can intensify if females have dependent young because of increased kill frequency (Bothma \& Coertze, 2004). Retaliatory killing can therefore be particularly pronounced for breeding females, and this can have significant negative effects on population persistence (Dalerum et al., 2008; Balme et al., 2009). Moreover, our data suggest that females are more likely than males to die from road accidents. This is surprising because we could expect that vehicle collisions are more common with males, which have wide-ranging behaviour that could increase collision risk (Taylor et al., 2002). Because our data come from many sources, this result may be an artefact caused by sampling bias (e.g. the majority of road kills come from one geographical area).

\section{Management implications}

Our study suggests equal survival of males and females, low survival outside protected areas and a high proportion of deaths attributed to people outside protected areas. Based on these findings, we suggest that (1) there is cause for concern regarding the sustainability of leopard populations in southern Africa because high female mortality may have severe demographic effects and a large proportion of suitable habitats do not lie within protected areas, and (2) management interventions have the potential to increase leopard survival dramatically because a large proportion of deaths were caused by people. For instance, mitigation actions such as the use of guard dogs, kraaling of livestock, and building fences could decrease conflict in farming areas, and financial incentives such as trophy hunting may increase local tolerance in game farming areas. However, we recommend that harvest quotas should be male biased because female leopards appear to be under considerable pressure from legal and illegal killing by people. As our analyses suggest that a higher incidence of females are involved in road accidents than males, we also recommend that road accident mitigation programmes are initiated. 


\section{Acknowledgements}

Funding for the project was received from the International Foundation of Science (D/4984-1), Wild Foundation (2008-011), Wilson Foundation and the University of Pretoria. LHS was further supported by the National Research Foundation (74819), FD by the National Research Foundation and a research fellowship from the University of Pretoria, and MJS by the Department of Science and Technology Centre of Excellence for Invasion Biology and the National Research Foundation. We thank three anonymous reviewers for their valuable comments.

\section{References}

Agresti, A. (2010) Analysis of Ordinal Categorical Data. Wiley, Hoboken, USA.

Andrén, H., Linnell, J.D.C., Liberg, O., Andersen, R., Danell, A., KARLSSON, J. et al. (2006) Survival rates and causes of mortality in Eurasian lynx (Lynx lynx) in multi-use landscapes. Biological Conservation, 131, 23-32.

B AILEy, T.N. (2005) The African Leopard: Ecology and Behaviour of a Solitary Felid. Columbia University Press, New York, USA.

BAKeR, J.D. \& Thompson, P.M. (2007) Temporal and spatial variation in age-specific survival rates of a long-lived mammal, the Hawaiian monk seal. Proceedings of the Royal Society B: Biological Sciences, 274, 407-415.

BALME, G.A. (2009) The conservation biology of a nominally protected leopard population. $\mathrm{PhD}$ thesis. University of Kwazulu-Natal, Durban, South Africa.

Balme, G.A., Batchelor, A., De Woronin Britz, N., Seymour, G., Grover, M., Hes, L. et al. (2013) Reproductive success of female leopards Panthera pardus: the importance of top-down processes. Mammal Review, 43, 221-237.

Balme, G.A., Hunter, L. \& Braczkowski, A.R. (2012) Applicability of age-based hunting regulations for African leopards. PLoS ONE, 7(4), e35209.

Balme, G.A., Slotow, R. \& Hunter, L.T.B. (2009) Impact of conservation interventions on the dynamics and persistence of a persecuted leopard (Panthera pardus) population. Biological Conservation, 142, 2681-2690.

Balme, G.A., Slotow, R. \& Hunter, L.T.B. (2010) Edge effects and the impact of non-protected areas in carnivore conservation: leopards in the Phinda-Mkhuze Complex, South Africa. Animal Conservation, 13, 315-323.

Bотнма, J. du P. \& Bотнма, M.D. (2006) Activity patterns in southern Kalahari leopards. African Zoology, 41, 150-152.

Bothma, J. du P. \& Coertze, R.J. (2004) Motherhood increases hunting success in southern Kalahari leopards. Journal of Mammalogy, 85, 756-760.

Bothma, J. du P., Knight, M.H., Le Riche, E.A.N. \& Van Hensbergen, H.J. (1997) Range size of southern Kalahari leopards. South African Journal of Wildlife Research, 27, 94-99.

Chase-Grey, J.N. (2011) Leopard population dynamics, trophy hunting and conservation in the Soutpansberg Mountains, South Africa. PhD thesis. Durham University, Durham, UK.

Christensen, R.H.B. (2011) Analysis of Ordinal Data with Cumulative Link Models: Estimation with the R-Package Ordinal. R-package version 2011.09-13. Http://cran.r-project.org/web/packages/ordinal/ vignettes/clm_intro.pdf [accessed 7 June 2012].
Crawley, M.J. (2002) Statistical Computing: An Introduction to Data Analysis Using S-plus. Wiley, Chichester, UK.

Creel, S. \& Rotella, J.J. (2010) Meta-analysis of relationships between human offtake, total mortality and population dynamics of gray wolves (Canis lupus). PLoS ONE, 5(9), e12918.

Dalerum, F., Shults, B. \& Kunkel, K. (2008) Estimating sustainable harvest in wolverine populations using logistic regression. The Journal of Wildlife Management, 72, 1125-1132.

EBerhardt, L.L. (2002) A paradigm for population analysis of long-lived vertebrates. Ecology, 83, 2841-2854.

Grambsch, P.M. \& Therneau, T.M. (1994) Proportional hazards tests and diagnostics based on weighted residuals. Biometrika, 81, 515-526.

Grimbeek, A.M. (1992) The ecology of the leopard (Panthera pardus) in the Waterberg. MSc thesis. University of Pretoria, Pretoria, South Africa.

Henschel, P., Hunter, L., Breitenmoser, U., Purchase, N., Packer, C., Khorozyan, I. et al. (2008) Panthera pardus. In The IUCN Red List of Threatened Species v. 2014.1. Http://www. iucnredlist.org [accessed 11 July 2014].

Hothorn, T., Bretz, F. \& Westfall, P. (2012) Multcomp: Simultaneous Inference for General Linear Hypotheses. R package v. 1.2-14. Http://cran.r-project.org/package $=$ multcomp [accessed 7 June 2012].

Hrdy, S.B. (1979) Infanticide among animals: a review, classification, and examination of the implications for the reproductive strategies of females. Ethology and Sociobiology, 1, 13-40.

Krebs, J., Lofroth, E., Copeland, J.P., Banci, V., Cooley, D., Golden, H. et al. (2004) Synthesis of survival rates and causes of mortality in North American wolverines. The Journal of Wildlife Management, 68, 493-502.

Martins, Q.E. (2010) The ecology of the leopard Panthera pardus in the Cederberg Mountains. PhD thesis. University of Bristol, Bristol, UK.

Murray, D.L. (2006) On improving telemetry-based survival estimation. The Journal of Wildlife Management, 70, 1530-1543.

Norton, P.M. \& Henley, S.R. (1987) Home range and movements of male leopards in the Cedarberg Wilderness Area, Cape Province. South African Journal of Wildlife Research, 17, 41-48.

Norton, P.M. \& Lawson, A.B. (1985) Radio tracking of leopards and caracals in the Stellenbosch area, Cape Province. South African Journal of Wildlife Research, 15, 17-24.

OWEn, C. (2006) Reproductive biology and population ecology of leopards (Panthera pardus) on Karongwe. MSc thesis. University of KwaZulu-Natal, Durban, South Africa.

Pollock, K.H., Winterstein, S.R., Bunck, C.M. \& Curtis, P.D. (1989) Survival analysis in telemetry studies: the staggered entry design. The Journal of Wildlife Management, 53, 7-15.

R Development Core Team (2011) R: A Language and Environment for Statistical Computing. R Foundation for Statistical Computing, Vienna, Austria. Http://www.R-project.org/ [accessed 1 January 2011].

Ripple, W.J. \& Beschta, R.L. (2012) Trophic cascades in Yellowstone: the first 15 years after wolf reintroduction. Biological Conservation, $145,205-213$.

Stander, P.E., Haden, P.J., Kaqece \& Ghau (1997) The ecology of asociality in Namibian leopards. Journal of Zoology, 242, 343-364.

STEIN, A.S. (2008) Ecology and conservation of the leopard (Panthera pardus Linnaeus 1758) in northcentral Namibia. PhD thesis. University of Massachusetts, Amherst, USA.

STEYN, V.P. (2008) The social-spatial organisation of leopards (Panthera pardus) in the Northern Tuli Game Reserve, Botswana. MTech thesis. Tswane University of Technology, Pretoria, South Africa. 
Steyn, V. \& Funston, P.J. (2006) A case of cannibalism in leopards. South African Journal of Wildlife Research, 36, 189-190.

Stoner, D.C., Wolfe, M.L. \& Choate, D.M. (2006) Cougar exploitation levels in Utah: implications for demographic structure, population recovery, and metapopulation dynamics. The Journal of Wildlife Management, 70, 1588-1600.

SwANEPOEL, L.H. (2009) Ecology and conservation of leopards, Panthera pardus, on selected game ranches in the Waterberg region, Limpopo, South Africa. MSc thesis. University of Pretoria, Pretoria, South Africa.

Swanepoel, L.H., Lindsey, P., Somers, M.J., van Hoven, W. \& Dalerum, F. (2013) Extent and fragmentation of suitable leopard habitat in South Africa. Animal Conservation, 16, 41-50.

Swenson, J.E., Sandegren, F., Soderberg, A., Bjarvall, A., Franzen, R. \& Wabakken, P. (1997) Infanticide caused by hunting of male bears. Nature, 386, 450-451.

Taylor, S.K., Roelke Parker, M.E., Rotstein, D.S., Buergelt, C.D. \& Homer, B.L. (2002) Causes of mortality of free-ranging Florida panthers. Journal of Wildlife Diseases, 38, 107-114.

Therneau, T. (2012) A Package for Survival Analysis in S. R package version 2.36-14. Http://cran.r-project.org/package=survival [accessed 8 June 2012].

Therneau, T. \& Grambsch, P.M. (2010) Modeling Survival Data: Extending the Cox Model (Statistics for Biology and Health). Springer-Verlag, New York, USA.

Thorn, M., Green, M., Dalerum, F., Bateman, P.W. \& Sсотт, D.M. (2012) What drives human-carnivore conflict in the North West Province of South Africa? Biological Conservation, 150, 23-32.

Treves, A. \& Karanth, K.U. (2003) Human-carnivore conflict and perspectives on carnivore management worldwide. Conservation Biology, 17, 1491-1499.

Weaver, J.L., Paquet, P.C. \& Ruggiero, L.F. (1996) Resilience and conservation of large carnivores in the Rocky Mountains. Conservation Biology, 10, 964-976.

Whitman, K., Starfield, A.M., Quadling, H.S. \& Packer, C. (2004) Sustainable trophy hunting of African lions. Nature, 428, $175-178$.

Woodroffe, R. \& Ginsberg, J.R. (1998) Edge effects and the extinction of populations inside protected areas. Science, 280 , 2126-2128.

\section{Biographical sketches}

Lourens Swanepoel, Michael Somers, Wouter van Hoven and Fredrik Dalerum are affiliated with the Centre for Wildlife Management at the University of Pretoria. Their research focuses on wildlife management, carnivore ecology and conservation, and functional aspects of biodiversity. Monika Schiess-Meier, Cailey Owen, Andrei Snyman, Quinton Martins, Charl Senekal, Gerrie Camacho and Willem Boshoff are all involved in carnivore research, conservation and management through various NGOs and governmental agencies. Their research mainly focuses on conflict mitigation actions, ecological research and extension work throughout South Africa and Botswana. 